\title{
Tahap Keyakinan Diri dalam Kalangan Pelajar Sarjana Muda Pendidikan, di Universiti Utara Malaysia
}

\author{
Self-Confidence Level among Education's Undergraduate in Universiti Utara Malaysia
}

\author{
Nurull Salmi Md. Dazali \& Isha Awang \\ Kolej Sastera dan Sains \\ Universiti Utara Malaysia \\ email: nurullsalmi86@gmail.com
}

\begin{abstract}
Abstrak
Keyakinan diri merupakan suatu elemen penting yang harus ada dan dikuasai oleh setiap pelajar, sama ada bagi memenuhi keperluan mereka ketika proses pelajaran, persiapan menempuh alam pekerjaan ataupun dalam interaksi sosial. Bagi memastikan usaha ini berjaya, guru sebagai agen perubahan dan perkembangan sahsiah diri pelajar terlebih dahulu perlu menguasai setiap aspek bagi membina keyakinan diri ketika berhadapan dengan pelbagai ragam pelajar mereka kelak. Justeru, kajian ini dijalankan untuk mengenal pasti tahap keyakinan diri dalam kalangan pelajar pendidikan sebagai persediaan mereka untuk menjadi guru. Kajian berbentuk tinjauan ini melibatkan seramai 152 orang sampel pelajar semester enam program Sarjana Muda Pendidikan dengan menggunakan borang soal selidik sebagai instrumen kajian. Secara keseluruhan, keputusan analisis menunjukkan tahap keyakinan diri adalah pada tahap yang tinggi. Hasil analisis Ujian-t $(\mathrm{t}=-0.62$, $\mathrm{p}>005)$, juga menunjukkan tidak terdapat perbezaan yang signifikan antara tahap keyakinan diri mengikut jantina. Selain itu, ujian korelasi menunjukkan keyakinan diri $(\mathrm{r}=0.56)$ mempunyai hubungan positif yang signifikan dengan pencapaian pelajar. Kesimpulanya, keyakinan diri tidak dipengaruhi oleh jantina tetapi ianya merupakan salah satu elemen bagi memperoleh pencapaian akademik yang cemerlang. Oleh itu, semua pihak yang terlibat perlu memberi perhatian serius dalam usaha membina keyakinan diri pelajar terutamanya di Universiti Awam bagi menyediakan tenaga kerja yang memenuhi kehendak pasaran kerja semasa.
\end{abstract}

Kata kunci keyakinan diri, pelajar pendidikan

\begin{abstract}
Self-confidence is an essential element that must be present and mastered by each student, whether to meet their needs during lessons, employment process or social interactions. To ensure this effort is successful, teacher as an agent in the change and development of students' personality must first master every aspect of building selfconfidence when dealing with their multifaceted future students. Therefore, this study was undertaken to determine the level of self-confidence among students of education to prepare them in becoming teachers. This survey study involves 152 samples of semester 6 Bachelor of Education program students using a questionnaire as an instrument. Overall, the results of the analysis showed that the level of self-confidence is at a high level. The results of t-test analysis ( $t=-0.62, p>005)$, showed no significant difference between the level of self-confidence by gender. In addition, the correlation test showed confidence $(r=0.56)$ had a significant positive relationship with student achievement. Conclusion, self-confidence is not affected by gender, but it is one of the elements for excellent academic achievement. Therefore, all parties involved need to pay serious attention to building self-confidence of students especially in universities to provide the workforce that meets the requirements of the current job market.
\end{abstract}

Keywords self-confidence, student teacher

\section{PENGENALAN}

Seiring dengan perubahan era globalisasi yang berasaskan pengetahuan kini, negara perlu membuat pelbagai strategi bermula daripada peringkat yang paling asas bagi menghasilkan aset yang berkualiti iaitu dalam bentuk sumber manusia. Menurut Azalya (2003), untuk berhadapan dengan arus global kini, setiap rakyat Malaysia perlu dilengkapi dengan dasar ilmu dan praktikal yang releven serta dilengkapi pelbagai 
kemahiran seperti hard skills dan soft skills. Penekanan dalam menguasai kemahiran-kemahiran generik haruslah bermula daripada peringkat sekolah dengan menerapkan kemahiran tersebut di dalam proses pelajaran dan pembelejaran (P\&P). Oleh yang demikian, kurikulum pendidikan haruslah sentiasa mengikut peredaran zaman bagi memastikan pelajar yang dihasilkan bukan sahaja mempunyai ilmu pengetahuan berasaskan teori semata-mata malah mampu mengaplikasikan teori tersebut ke dalam kehidupan seharian berserta dengan menguasai kemahiran-kemahiran generik yang sepatutnya bagi menghadapi era globalisasi pada masa kini.

Secara umumnya, program pendidikan guru di semua Institut Pengajian Tinggi (IPT) dan BPG memiliki kesamaan dari segi komponen-komponen kursus yang ditawarkan. Kurikulum program pendidikan boleh dibahagikan kepada dua iaitu teori dan praktikal. Kurikulum teori termasuklah komponen-komponen kursus seperti asas, teras, elektif dan umum. Manakala praktikal merupakan amali atau lebih dikenali sebagai latihan mengajar (LM). Di banyak negara pula, program pendidikan guru terdiri daripada dua komponen utama iaitu kerja kursus dan komponen amali (Anderson, 1995). Dalam melahirkan seorang guru yang mampu mendidik generasi masa hadapan, bakal-bakal guru didedahkan dengan pelbagai pengetahuan dan kemahiran terlebih dahulu sebelum mereka menjalani latihan mengajar.

\section{LATAR BELAKANG KAJIAN}

Guru sebagai agen perubahan perlu bersifat lebih kreatif dan inovatif agar proses P\&P mampu menjadi efektif dan berkesan. Kamus Dewan edisi ke-4 (2005), kreatif bermakna keupayaan seseorang mencuba, menghasilkan dan memperkembangkan sesuatu manakala inovatif merujuk kepada keupayaan seseorang bagi membina atau melahirkan sesuatu yang baru sama ada dari segi kaedah, sistem pendekatan atau sebagainya. Para pelajar akan merasa tidak seronok, bosan, jemu dan hilang minat untuk belajar jika guru ketandusan unsur kreatif ketika menjalankan sesi P\&P. Sesuatu subjek itu juga dianggap stereotaip, tidak mencabar dan statik jika guru tidak berjaya menyuntik idea inovasi dan pembaharuan yang berterusan (Kadir, 2004).

Sehubungan itu, keyakinan diri perlu ada dalam diri setiap guru bagi mewujudkan sifat kreatif dan inovatif. Hal ini kerana, kreativiti dan inovatif lahir dari dalaman yang memerlukan keyakinan diri bagi menjadikan sesuatu idea baru itu mampu diaplikasikan daripada imaginasi kepada nyata (Yeung, 2008). Bermula pada tahun 1997, sekolah bestari telah diwujudkan. Kewujudan sekolah bestari menekankan penggunaan teknologi maklumat dan komunikasi (ICT) bagi meningkatkan aspek kreatif dan inovatif kepada para guru dalam menjalankan proses $\mathrm{P} \& \mathrm{P}$ di samping memperluaskan ilmu dan pengetahuan (Adnan, 2011). Oleh yang demikian, guru perlu memilih teknik pengajaran yang mampu membuatkan pelajar berminat dan merangsang untuk belajar di samping mencabar kebolehan pelajar, berjaya melepaskan horizon intelektual, sosial, moral, kerohanian dan mewujudkan perspektif positif seperti merasa penting untuk dipelajari serta berguna untuk masa hadapan.

\section{Keyakinan Diri}

Keyakinan diri merupakan satu faktor yang dapat mempengaruhi kejayaan dan kegagalan dalam hidup seseorang (Ibrahim et al., 2005). Individu yang memiliki tahap keyakinan yang tinggi akan lebih berjaya kerana mereka berani berhadapan dengan segala cabaran bagi menempa kejayaan hidup yang lebih cemerlang. Menurut Adil (2003) pula, keyakinan diri bermaksud kepercayaan kepada diri sendiri. Manakala Yeung (2008), mendefinisikan keyakinan diri sebagai keupayaan seseorang untuk menentukan keputusan atau bertindak secara berkesan tanpa rasa takut kepada segala cabaran. Ini menunjukkan keyakinan diri ialah penggabungan antara fikiran dan perasaan. Individu yang memiliki tahap keyakinan diri yang tinggi akan merangsang pemikiran positif dengan memandang setiap sesuatu sebagai peluang untuk berjaya dan menolak perasaan negatif yakni tidak menjadikan setiap masalah sebagai penghalang kepada cita-cita (Al-Aqsar, 2005).

Selain itu, keyakinan diri juga adalah merujuk kepada suatu kualiti diri yang amat diperlukan oleh seseorang dan ianya agak susah diukur terutamanya dalam diri individu lain (Litvinoff, 2005). Menurut 
Adil (2003), melalui prinsip dorongan peribadi yakni mendorong kepada peneguhan yang berkesinambungan di dalam fikiran akan dapat merangsang fizikal dan akhirnya membantu membina keyakinan diri seseorang. Ini bermakna keyakinan diri boleh dibina melalui faktor persekitaran dan dorongan daripada individu lain. Faktor-faktor ini akan merangsang pemikiran seseorang dan akhirnya diterjemahkan melalui tindakan.

\section{Hubungan Keyakinan Diri dengan Jantina}

Kajian yang dibuat oleh Donofrio dan Davis (2007) terhadap 504 orang pelajar tahun akhir di salah sebuah institusi di Jerman mendapati bahawa tahap keyakinan pelajar adalah sama secara keseluruhannya. Ini menunjukkan bahawa setiap pelajar mempunyai tahap keyakinan diri yang sama tidak kira kaum lelaki atau perempuan.

Selain itu, kajian yang dilakukan oleh Zareh (1994) terhadap 150 pelajar iaitu 75 orang pelajar perempuan dan 75 orang pelajar lelaki di sekolah menengah Dareh Shar yang terletak di Bandar Iran, dengan menggunakan Cooper Smeit's questionnaire bagi menguji perbezaan tahap kemahiran keyakinan diri mengikut jantina. Beliau mendapati bahawa terdapat perbezaan yang signifikan antara tahap kemahiran pelajar perempuan dengan pelajar lelaki. Ini disokong dengan dapatan kajian yang dilakukan oleh Emamzadeh (2004) yang menunjukkan bahawa pelajar lelaki menunjukkan tahap keyakinan diri yang lebih tinggi daripada pelajar perempuan. Dalam kajian beliau terhadap 72 orang pelajar yang terdiri daripada 37 orang pelajar lelaki dan 35 orang pelajar perempuan di sebuah universiti di Iran turut membuktikan bahawa tahap keyakinan diri dalam diri setiap pelajar adalah berbeza. Selain itu, satu kajian meramal perbezaan tahap keyakinan diri yang mendorong kepintaran pelajar oleh Naderi dan rakan-rakan (2008) menunjukkan hasil analisis kajian adalah signifikan mengikut jantina. Ini menunjukkan bahawa terdapat perbezaan antara tahap kemahiran pelajar lelaki dengan pelajar perempuan.

\section{Hubungan Keyakinan Diri dengan Prestasi Kerja Guru}

Keyakinan diri juga menjadi nadi dalam aktiviti seharian seseorang. Hal ini kerana segala aktiviti yang melibatkan pergaulan atau membina hubungan dengan individu lain menghendaki seseorang itu untuk berkomunikasi. Komunikasi pula wujud jika seseorang itu mempunyai keyakinan diri untuk memulakan sesuatu perhubungan. Bagi aspek pendidikan, kekangan komunikasi yang wujud akan menyebabkan masalah besar dalam proses P\&P. Guru yang gagal memiliki keyakinan diri dalam berkomunikasi akan membuatkan ilmu yang diajar tidak sampai kepada para pelajarnya. Manakala, bagi pelajar pula, kegagalan mereka membina keyakinan diri dalam berkomunikasi akan menyebabkan mereka bersifat pasif serta kurang mengarahkan diri bagi mencapai potensi diri sepenuhnya dan akhirnya memberi kesan kepada pencapaian akademik mereka (Zakaria, 2004).

Seiring dengan kepesataan teknologi kini, bidang pendidikan juga tidak terkecuali menerima tempiasnya. Proses P\&P juga menggunakan medium teknologi dalam menyampaikan ilmu kepada pelajar. Oleh yang demikian, guru seharusnya mahir menggunakan teknologi. Kemahiran ini memerlukan guru berkeyakinan untuk mencuba sesuatu yang baru. Pelajar juga perlu mempunyai keyakinan yang sama bagi memastikan proses P\&P dapat dijalankan secara berkesan. Satu kajian yang telah dijalankan di Fakulti Pendidikan, Universiti Putra Malaysia (UPM) mendapati guru baru mengalami masalah yang besar ketika menjalankan proses P\&P (Azlan \& Hazriani, 2010). Hal ini kerana, proses P\&P memerlukan guru bijak merancang kaedah mengajar, membuat perancangan pengajaran dan menyediakan bahan bantu mengajar secara kreatif dan inovatif bagi menarik minat pelajar. Mooney dan Jones (2002) juga menyatakan bahawa tahap keyakinan diri yang rendah dalam kalangan guru baru menyebabkan masalah lain seperti masalah pengurusan kelas, ketidakmampuan dalam merancang aktiviti pembelajaran dan kurang penguasaan subjek yang diajar. Kajian mereka ke atas guru baru mendapati content knowledge, pedagogical knowledge dan pedagogical content knowledge adalah merupakan aspek yang perlu diberi penekanan dan dikuasai dalam membina keyakinan guru bagi menjadi seorang guru yang mahir. Ini kerana kejayaan sesuatu pengajaran yang disampaikan oleh guru di dalam kelas bergantung sepenuhnya 
kepada kebijaksanaan guru membuat perancangan dan persediaan rapi sebelum memulakan sesi pengajaran.

Selain itu, faktor keyakinan diri juga boleh mempengaruhi sikap seseorang (Ramli, 2009). Dalam kajiannya terhadap 131 guru Bahasa Melayu di Kuala Terengganu, mendapati wujud hubungan yang signifikan antara keyakinan dengan sikap $(\mathrm{r}=0.95)$. Ini menunjukkan guru yang mempunyai tahap keyakinan diri yang tinggi akan menunjukkan sikap positif. Sikap yang positif ini perlu terutamanya bagi menangani pelajar yang lemah dan bermasalah dalam membantu mereka berjaya sama ada dari aspek akademik mahu pun sahsiah diri.

\section{Hubungan Keyakinan Diri dengan Pencapaian Akademik Pelajar}

Melalui satu kajian yang dilakukan oleh Farahiyah (2013) terhadap pelajar dan pensyarah diploma di Politeknik mendapati bahawa pelajar yang memiliki tahap keyakinan diri yang rendah lebih bersifat pasif dan kurang berkeinginan untuk berjaya. Dapatan kajian ini juga menunjukkan terdapatnya hubungan positif yang wujud antara tahap keyakinan diri dengan pencapaian pelajar $(\mathrm{r}=0.74)$. Ini menunjukkan pelajar yang mempunyai tahap keyakinan diri yang tinggi akan lebih berjaya dari segi akademik. Situasi ini akan lebih membimbangkan jika para guru tidak berusaha untuk mengambil inisiatif bagi membantu pelajar tersebut membina keyakinan diri mereka. Selain itu, mereka yang mempunyai masalah keyakinan diri juga akan mengalami masalah emosi seperti sifat murung, bimbang dan sukar mengawal amarah kemarahan dan akhirnya akan mengganggu tahap prestasi akademik pelajar (Anthony, 2008).

\section{PENYATAAN MASALAH}

Sikap guru yang hanya mengajar sambil lewa dan tidak berusaha menjadikan P\&P sesuatu proses yang menyeronokkan akan memberi masalah kepada sistem pendidikan negara (Habibah \& Noran, 2002). Punca utama proses P\&P tidak berjaya menarik minat pelajar adalah kerana guru tidak mempunyai keyakinan diri untuk membuat sesuatu perkara yang baru (Adil, 2003). Stereotaip pembelajaran guru yang lebih bersifat menulis dan membaca daripada buku teks menyebabkan pelajar mudah bosan.

Keyakinan diri adalah sesuatu faktor yang mampu mempengaruhi identiti dan emosi seseorang (Anthony, 2008). Menurut Baharin \& Azura (2008), masalah utama yang sering dirujuk kepada pakar psikologi oleh pelajar adalah berkenaan kurangnya kelemahan dalam keyakinan diri. Menurut Nordin \& Abdul Rani (1995), kurangnya keyakinan diri seseorang itu boleh membangkitkan rasa bimbang dan risau yang akhirnya boleh mengganggu kelancaran aktiviti atau pekerjaan mereka. Oleh yang demikian, adalah dikhuatiri jika guru tidak memiliki tahap keyakinan diri yang tinggi akan menyebabkan mereka tidak dapat menjalankan tanggungjawab mereka sebagai pendidik dengan baik. Keyakinan diri boleh dibina jika guru mampu menguasai ilmu pengetahuan dan kemahiran secara teori dan amali mengenai subjek yang ingin diajar (Guay et al., 2003).

Senario kini menyaksikan kepesatan penggunaan teknologi dalam semua bidang termasuklah bidang pendidikan. Oleh yang demikian, golongan guru tidak terkecuali dalam arus teknologi kini. Masalah timbul apabila ada segelintir guru yang kurang berkeyakinan untuk menggunakan kemudahan teknologi ini (Farahiyah, 2013). Ianya merupakan sesuatu yang baru namun guru perlu mahir menggunakannya.

Menurut Zakaria et al. (2001), kebanyakan guru pelatih tidak dapat mengaplikasikan kaedahkaedah yang telah dipelajari sebelumnya ketika di institusi pengajian tinggi ke dalam kelas sebenar semasa di sekolah. Ini mungkin dipengaruhi oleh faktor kesediaan pelajar. Beth Southwell dan Allan L. White (2005) dalam kajiannya yang bertajuk 'Attitudes versus Achievement in Pre-service Mathematics Teacher Education' memberikan statistik seperti berikut: 83\% responden bersetuju dengan pernyataan "Saya yakin dengan kaedah pengajaran matematik yang saya gunakan" manakala sebanyak $71 \%$ tidak bersetuju dengan pernyataan "Saya kurang pasti tentang apa yang saya lakukan semasa mengajar subjek matematik". Selain itu, kajian yang dilakukan oleh General Teaching Council for England (GTC) (2006), menunjukkan hanya $57 \%$ guru pelatih berasa yakin terhadap latihan yang dijalani yakni latihan untuk mengajar dengan baik. 
Ini jelas menunjukkan sistem pendidikan masih ketandusan pendidik yang memiliki keyakinan pada pengajaran, memiliki kekuatan untuk menghadapi cabaran dan pembaharuan dalam sistem pendidikan dan dalam menjalankan tugas dengan baik yakni dengan menerapkan sikap yang produktif untuk memperkembang potensi diri. Oleh yang demikian, kajian ini dijalankan bagi melihat tahap keyakinan diri graduan bakal guru yang akan dihasilkan oleh Universiti Utara Malaysia.

\section{OBJEKTIF KAJIAN}

Objektif utama kajian ini adalah untuk:

1. Mengenal pasti tahap keyakinan diri dalam kalangan pelajar semester enam Sarjana Muda Pendidikan, UUM.

2. Mengkaji perbezaan tahap keyakinan diri antara jantina.

3. Mengenal pasti hubungan antara tahap keyakinan diri dengan pencapaian pelajar.

\section{SOALAN KAJIAN}

1. Apakah tahap keyakinan diri dalam kalangan pelajar semester enam Sarjana Muda Pendidikan, UUM?

2. Adakah terdapat perbezaan tahap keyakinan diri pelajar mengikut jantina?

3. Adakah terdapat hubungan antara tahap keyakinan diri dengan pencapaian pelajar?

\section{METODOLOGI}

Kajian ini telah dijalankan di Kolej Sastera dan Sains, UUM. Ianya melibatkan seramai 245 orang pelajar tahun tiga Sarjana Muda Pendidikan. Jadual Krejcie dan Morgan (1970) menunjukkan bahawa jika saiz populasi berjumlah di antara 241 dan 250 orang, maka jumlah saiz sampelnya adalah 152 orang. Oleh itu, mengikut kaedah sampel berstrata proponsional, jumlah sampel yang diambil daripada setiap strata adalah mengikut jumlah responden yang terdapat di dalam strata terbabit.

Kajian ini berbentuk kajian penerangan secara deskriptif yang berbentuk tinjauan menggunakan pendekatan kuantitatif dengan borang soal selidik dijadikan sebagai instrumen kajian. Justeru, dalam kajian ini penyelidik telah menggunakan soal selidik yang dibina oleh Adibah (2005). Bagi memastikan kebolehpercayaan instrumen yang digunakan, penyelidik telah menjalankan satu kajian rintis dan dapatan kajian tersebut menunjukkan nilai kebolehpercayaan yang tinggi, iaitu dengan nilai kebolehpercayaan 0.89 .

Soal selidik yang dikumpulkan akan dianalisis melalui komputer menggunakan pengisian windows Statistical Package For Social Science (SPSS) version 20.0 bagi mendapatkan data yang tepat. Dapatan analisis dipaparkan dalam bentuk jadual yang menunjukkan kekerapan dan peratusan. Soal selidik ini terbahagi kepada dua bahagian. Bahagian A (demografi pelajar), pengkaji menggunakan min purata daripada analisis statistik deskriptif. Ia akan dianalisis mengikut jantina, kaum dan aliran pengajian. Analisis ini hanya memberi gambaran secara menyeluruh di mana daripada analisis ini dapat diketahui jantina, kaum atau aliran pengajian yang mana mempunyai tahap kemahiran kayakinan diri yang tinggi.

Bahagian B (Kemahiran Generik) pula data dianalisis secara analisis statistik inferensi iaitu menggunakan korelasi dan ujian t-bebas untuk mengukur hipotesis yang dibina. Analisis secara infrensi ini digunakan untuk melihat perbezaan antara tahap keyakinan diri dengan jantina dan hubungan antara keyakinan diri dan CGPA. 


\section{DAPATAN KAJIAN}

Analisis deskriptif adalah digunakan untuk mengenal pasti latar belakang pelajar mengikut jantina, kaum dan aliran pengajian, menganalisis data mengikut bahagian dalam soal selidik, menganalisis tanggapan pelajar terhadap tahap keyakinan dalam diri, menganalisis keseluruhan tahap keyakinan diri, menganalisis perbandingan skor min kemahiran keyakinan diri berdasarkan jantina dan menganalisis perbandingan skor min kemahiran keyakinan diri berdasarkan kaum.

\section{Latar Belakang Pelajar Mengikut Jantina, Kaum dan Aliran Pengajian}

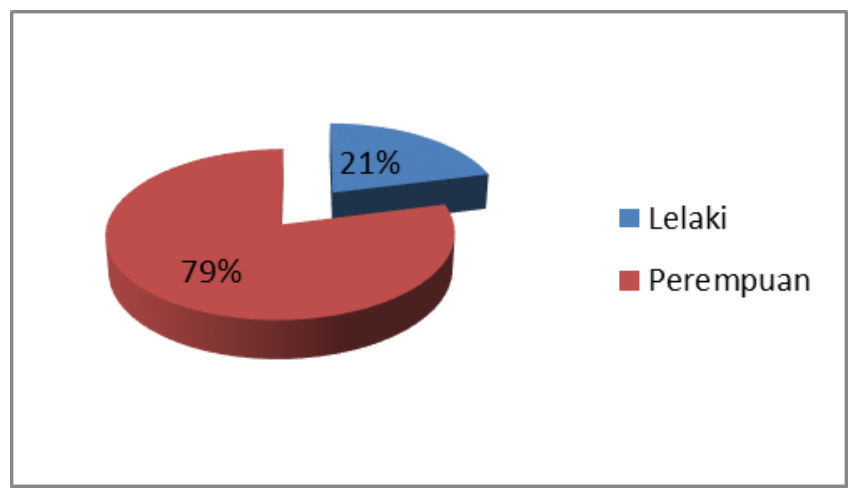

Rajah 1 Peratusan responden mengikut jantina

Rajah 1 menunjukkan taburan kekerapan responden mengikut jantina. Jumlah keseluruhan responden bagi kajian ini adalah seramai 152 orang. Majoriti responden adalah responden perempuan iaitu seramai 120 orang atau $79 \%$ berbanding dengan responden lelaki yang terdiri daripada seramai 32 orang dengan peratusan $21 \%$ sahaja. Perbezaan ini sangat ketara, namun ia merupakan fenomena biasa yang berlaku dalam institusi pengajian tinggi kini di mana kebanyakan penuntutnya adalah kaum wanita.

Jadual 1 menunjukkan taburan kekerapan dan peratusan responden Kemahiran Keyakinan Diri dengan pernyataan pertama "Saya seorang yang berfikiran positif" mendapat kesemua jenis respon iaitu tertinggi ialah daripada 86 orang atau $56.6 \%$ yang bersetuju, diikuti 55 orang atau $36.2 \%$ yang sangat setuju kemudian 11 orang atau $7.2 \%$ yang kurang setuju dengan pernyataan ini. Nilai min pernyataan ini adalah 4.29 dan nilai sisihan piawai adalah 0.594 .

Jadual 1 Taburan tahap keyakinan diri responden

\begin{tabular}{|c|c|c|c|c|c|c|c|}
\hline \multirow{2}{*}{ Pernyataan } & STS & TS & KS & $\mathbf{S}$ & SS & \multirow{2}{*}{ Min } & \multirow{2}{*}{ SP } \\
\hline & 1 & 2 & 3 & 4 & 5 & & \\
\hline \multirow{2}{*}{$\begin{array}{l}\text { Saya seorang yang } \\
\text { berfikiran positif. }\end{array}$} & & & 11 & 86 & 55 & \multirow[t]{2}{*}{4.29} & \multirow[t]{2}{*}{0.594} \\
\hline & & & $7.2 \%$ & $56.6 \%$ & $36.2 \%$ & & \\
\hline \multirow{2}{*}{$\begin{array}{l}\text { Saya seorang yang } \\
\text { komitmen } \\
\text { menjaga kehormatan } \\
\text { dan maruah. }\end{array}$} & & & 7 & 66 & 79 & \multirow[t]{2}{*}{4.47} & \multirow[t]{2}{*}{0.586} \\
\hline & & & $4.6 \%$ & $43.4 \%$ & $52 \%$ & & \\
\hline \multirow{2}{*}{$\begin{array}{lc}\text { Saya } & \text { seorang } \\
\text { yakin } & \text { kepada } \\
\text { sendiri. } & \end{array}$} & & 2 & 17 & 79 & 54 & \multirow[t]{2}{*}{4.22} & \multirow[t]{2}{*}{0.690} \\
\hline & & $1.3 \%$ & $11.2 \%$ & $52.0 \%$ & $35.5 \%$ & & \\
\hline
\end{tabular}




\begin{tabular}{|c|c|c|c|c|c|c|}
\hline \multirow{2}{*}{$\begin{array}{l}\text { Saya mempunyai kualiti } \\
\text { dari aspek keyakinan. }\end{array}$} & 1 & 18 & 83 & 50 & 4.2 & 0.662 \\
\hline & $0.7 \%$ & $11.8 \%$ & $54.6 \%$ & $32.9 \%$ & & \\
\hline Purata & & & & & 4.29 & 0.544 \\
\hline $\begin{aligned} * 1 & =\text { Sangat tidak set } \\
2 & =\text { Tidak setuju } \\
3 & =\text { Kurang setuju } \\
4 & =\text { Setuju } \\
5 & =\text { Sangat setuju }\end{aligned}$ & & & & & & \\
\hline
\end{tabular}

Bagi pernyataan "Saya seorang yang komitmen dalam menjaga kehormatan dan maruah" pula, seramai 79 orang atau $52 \%$ yang sangat setuju diikuti respon bersetuju daripada 66 orang atau $43.4 \%$. Seterusnya sebanyak $4.6 \%$ atau 7 orang responden kurang setuju dengan pernyataan ini. Nilai min pernyataan ini ialah 4.47 dan nilai sisihan piawai adalah 0.586 .

Pernyataan item seterusnya ialah "Saya seorang yang yakin kepada diri sendiri." Seramai 79 orang (52\%) menyatakan setuju, manakala seramai 54 orang (35.5\%) menyatakan sangat setuju dan 17 orang (11.2\%) mengatakan kurang setuju. Selebihnya iaitu 2 orang (1.3\%) mengatakan tidak setuju. Nilai min bagi item ini ialah 4.22 dan nilai sisihan piawai adalah 0.690 .

Pernyataan "Saya mempunyai kualiti dari aspek keyakinan" pula mendapat respon setuju sebanyak $54.6 \%$ atau 83 orang dan 50 orang atau $32.9 \%$ pula sangat bersetuju. Pernyataan ini kurang dipersetujui oleh 18 orang atau $11.8 \%$ responden manakala seorang atau $0.7 \%$ pula tidak setuju dengan pernyataan ini. Nilai min dan nilai sisihan piawai adalah masing-masing 4.20 dan 0.662 . Manakala purata min keseluruhan pernyataan ialah 4.29 dan nilai sisihan piawai adalah 0.544 .

\section{Analisis Perbandingan Skor Min Kemahiran Keyakinan Diri Berdasarkan Jantina}

Analisis secara perbandingan skor min telah digunakan untuk mengenal pasti tahap keyakinan diri berdasarkan jantina.

Jadual 2 Analisis kemahiran keyakinan diri mengikut jantina

\begin{tabular}{llrlc}
\hline \multirow{3}{*}{ Yakin diri } & \multicolumn{1}{c}{ Jantina } & \multicolumn{1}{c}{ N } & Min & Sisihan Piawai \\
\cline { 2 - 5 } & Lelaki & 30 & 4.258 & 0.519 \\
& Perempuan & 120 & 4.325 & 0.530 \\
\hline
\end{tabular}

Jadual 2 menunjukkan bahawa jumlah pelajar perempuan adalah lebih tinggi iaitu sebanyak 120 orang berbanding dengan pelajar lelaki yang hanya sebanyak 30 orang sahaja. Min skor tahap kemahiran keyakinan diri bagi pelajar perempuan iaitu 4.33 adalah lebih lebih tinggi berbanding dengan min skor pelajar lelaki yakni 4.26 .

Ini menunjukkan pelajar perempuan lebih mempunyai keyakinan diri yang tinggi berbanding dengan pelajar lelaki. Walau bagaimanapun, perbezaan ini adalah tidak signifikan seperti yang ditunjukkan dalam Jadual 3.

Ho1: Tidak terdapat perbezaan yang signifikan antara tahap Kemahiran Keyakinan Diri antara pelajar lelaki dan pelajar perempuan.

Berdasarkan Jadual 3, didapati tahap keyakinan diri bagi pelajar pendidikan lelaki dan perempuan tidak berbeza secara signifikan ( $\mathrm{t}=-0.62, \mathrm{p}>005)$. Keputusan ini menerima Ho1, iaitu tidak terdapat perbezaan yang signifikan antara tahap keyakinan diri antara jantina. 
Jadual 3 Ujian-t kemahiran keyakinan diri mengikut jantina

\begin{tabular}{|c|c|c|c|}
\hline & \multicolumn{3}{|c|}{ Ujian-t } \\
\hline & & df & Sig. 2 Hujung \\
\hline Keyakinan Diri & -0.619 & 148 & 0.106 \\
\hline
\end{tabular}

\section{Hubungan Keyakinan Diri dengan Pencapaian Akademik}

H02: Terdapat hubungan yang signifikan antara tahap keyakinan diri dengan pencapaian pelajar.

Ujian korelasi menunjukkan kemahiran keyakinan diri mempunyai hubungan positif yang signifikan $(\mathrm{r}=0.56)$ secara statistik dengan pencapaian pelajar. Keputusan ujian ini berjaya menolak Ho dan menerima H1. Ini menunjukkan pelajar yang mempunyai tahap kemahiran keyakinan diri yang tinggi mempunyai pencapaian yang tinggi dalam peperiksaan manakala pelajar yang mempunyai tahap kemahiran keyakinan diri yang rendah mempunyai pencapaian yang rendah dalam peperiksaan. Tahap kemahiran keyakinan diri menunjukkan hubungan yang rendah iaitu 0.56 terhadap pencapaian pelajar. Tahap kemahiran keyakinan diri menunjukkan nilai $\mathrm{r}^{2}=0.31$. Ini menunjukkan kemahiran keyakinan diri menyumbang sebanyak $31.4 \%$ varians berhubungan dengan varians pencapaian pelajar.

\begin{tabular}{clr} 
Jadual 4 Analisis korelasi antara tahap keyakinan diri dengan pencapai \\
& \multicolumn{2}{c}{ KeyakinanDiri } \\
\multirow{2}{*}{ Spearman's rho } & CGPA & 0.56 \\
& Sig. (2-ekor) & $0.004(* *)$ \\
& $\mathrm{N}$ & 150 \\
\hline ** Korelasi adalah signifikan pada aras 0.01 (2-ekor) &
\end{tabular}

\section{PERBINCANGAN}

Secara keseluruhannya, kajian ini menjawab persoalan kajian dan hipotesis kajian seperti yang dinyatakan. Tahap kemahiran keyakinan diri menunjukkan skor min yang tinggi iaitu sebanyak 4.29. Selain itu, tidak wujud perbezaan antara jantina dan kaum. Manakala, bagi hubungan dengan pencapaian pelajar, kemahiran keyakinan diri menunjukkan mempunyai hubungan yang positif dengan pencapaian pelajar.

Pernyataan item yang mempunyai min tertinggi bagi kemahiran keyakinan diri adalah "Saya seorang yang komitmen dalam menjaga kehormatan dan maruah" yakni dengan min 4.47. Seterusnya ialah pernyataan item "Saya seorang yang berfikiran positif" dengan min sebanyak 4.29 dan ianya masih dikategorikan berada pada tahap tinggi.

Pernyataan item yang mempunyai min terendah bagi konstruk ini ialah "Saya mempunyai kualiti dari aspek keyakinan". Nilai min adalah pada tahap tinggi iaitu 4.20. Walaupun masih menunjukkan berada pada tahap tinggi, namun pernyataan item ini adalah terendah yang diberi skor oleh responden. Dapatan ini jelas menunjukkan, masalah besar bagi seseorang pelajar adalah dari aspek keyakinan diri. Sebilangan besar pelajar masih kurang yakin dan kurang mempunyai persediaan untuk menceburi alam pekerjaan. Tahap keyakinan diri yang tinggi seharusnya dimiliki dan dipupuk semasa menuntut di menara gading oleh setiap pelajar sebagai persediaan memasuki alam pekerjaan dan akhirnya mampu menunjukkan prestasi kerja yang cemerlang (Raof \& Sharifah, 2003).

Pergaulan dan interaksi terutamanya dalam Bahasa Inggeris perlu diberi perhatian. Hal ini kerana apabila seseorang individu itu mampu memiliki perlbagai kemahiran terutamanya dalam aspek komunikasi, ia secara tidak langsung mampu meningkatkan tahap keyakinan diri mereka hasil daripada pergaulan dan hubungan kerjasama yang mudah dengan orang lain. Komunikasi dalam Bahasa Inggeris contohnya mampu membina keyakinan diri seseorang individu. Ini bersesuaian dengan kehendak kehidupan kini yang lebih menjurus kepada penggunaan Bahasa Inggeris dalam membuat sesuatu urusan 
atau perbincangan. Keyakinan diri yang tinggi mampu untuk menarik minat majikan untuk menawarkan pekerjaan kepada seseorang individu pelajar (Hashamiza, 2004).

Aktiviti pembentangan merupakan aktiviti pembelajaran yang bersifat formal di universiti. Dapatan kajian membuktikan bahawa pelajar adakalanya masih gugup ketika berhadapan dengan penonton yang ramai ketika melakukan pembentangan. Pelajar juga kurang mahir dalam menjawab persoalan yang dikemukakan oleh audiens. Dapatan ini bertepatan dengan pendapat yang dikemukakan Meriam (2007) yang menyatakan antara penyebab graduan gagal dalam sesi temuduga adalah kerana mereka gagal meyakinkan majikan dengan kelebihan diri masing-masing. Mereka juga gagal untuk memberi pendapat yang bernas bagi sesuatu isu walaupun antara mereka mempunyai kelulusan akademik yang cemerlang. Justeru itu, jelaslah kelulusan akademik dan teknikal perlulah juga dilengkapi dengan kemahiran keyakinan diri yang berkesan.

Berdasarkan analisis statistik dengan menggunakan ujian-t, pada aras signifikan 0.05 didapati bahawa tidak terdapat perbezaan yang signifikan antara kemahiran berkeyakinan diri mengikut jantina. Bandingan secara skor min antara pelajar lelaki dan perempuan juga tidak terlalu ketara. Iaitu 4.26 bagi lelaki dan 4.32 bagi perempuan di mana ianya hanya menunjukkan beza sebanyak 0.06 sahaja. Peranan universiti perlu menyediakan peluang pembelajaran yang bermakna, selain daripada mengasah keupayaan pelajar dengan kemahiran interpersonal, kemahiran berfikir mampu untuk membina tahap keyakinan diri dalam kalangan pelajar lelaki dan juga perempuan. Ini menunjukkan bahawa setiap pelajar perlu mempunyai tahap keyakinan diri yang sama tidak kira kaum lelaki atau perempuan. Namun apa yang membezakan mereka adalah faktor persekitaran yang lain yang merupakan salah satu faktor yang menyokong tahap keyakinan diri mereka. Contohnya, individu yang mudah bergaul dengan orang lain, mempunyai kemahiran berkomunikasi dengan baik, dibesarkan dalam suasana hidup yang selesa dan teratur akan menunjukkan tahap keyakinan diri yang tinggi tidak kira sama ada lelaki mahu pun perempuan (Barnett, 1994).

Namun, dapatan kajian ini bercanggah dengan hasil kajian yang dilakukan oleh Zareh (1994) dan Emamzadeh (2004). Kajian mereka menunjukkan bahawa pelajar lelaki menunjukkan tahap keyakinan diri yang lebih tinggi daripada pelajar perempuan. Selain itu, satu kajian meramal perbezaan tahap keyakinan diri yang mendorong kepintaran pelajar oleh Naderi dan rakan-rakan (2008) menunjukkan hasil analisis kajian adalah signifikan mengikut jantina. Ini menunjukkan bahawa terdapat perbezaan antara tahap kemahiran pelajar lelaki dengan pelajar perempuan. Dapatan ini seiring dengan kenyataan oleh Suraiya (2011) di mana beliau menyatakan bahawa lelaki diciptakan sebagai seorang pemimpin. Oleh itu, pada dasarnya seorang pemimpin itu perlu mempunyai tahap keyakinan diri yang tinggi bagi membolehkan individu tersebut memimpin orang bawahannya.

Hasil kajian juga menunjukkan kemahiran keyakinan diri mempunyai hubungan positif yang signifikan $(\mathrm{r}=0.56)$ secara statistik dengan pencapaian pelajar. Ini menunjukkan kemahiran keyakinan diri menyumbang sebanyak $31.4 \%$ varians berhubungan dengan varians pencapaian pelajar. Kenyataan yang dikeluarkan oleh Shahabudin dan Rohizani (2003) menyatakan bahawa individu yang mempunyai tahap keyakinan diri yang tinggi berpotensi untuk memiliki kemahiran generik yang lain seperti berkomunikasi, menyelesaikan masalah, menjadi fleksibel dan sebagainya. Ini kerana, individu ini berkeupayaan untuk memajukan diri mereka dalam apa jua cara. Kenyataan ini adalah selari dengan dapatan kajian ini yang menunjukkan bahawa terdapat hubungan yang signifikan antara tahap kemahiran keyakinan diri dengan prestasi pelajar. Ini menunjukkan pelajar yang mempunyai tahap keyakinan diri yang tinggi akan menunjukkan prestasi pelajaran yang tinggi. Ini kerana pelajar ini sentiasa berusaha untuk mempertingkatkan keupayaan diri dalam setiap aspek. Pelajar ini mampu mewujudkan komunikasi dua hala dan hubungan yang sihat dengan rakan sekelas serta guru.

\section{KESIMPULAN}

Pengajaran merupakan satu aktiviti khas dan kompleks. Apabila guru-guru pelatih dihantar ke sekolah untuk menjalani Latihan Mengajar, mereka telah menghadapi kejutan budaya. Guru pelatih mula keliru dengan tujuan latihan mengajar serta pengajarannya yang akan digredkan. Ini kerana guru pelatih mendapati teori yang dipelajari semasa di universiti tidak dapat dipraktikkan. Realiti sebenar memberikan masa yang lama kepada guru pelatih untuk menyesuaikan dengan persekitaran sekolah. Selain itu, 
jangkaan-jangkaan guru pelatih yang terlalu tinggi terhadap pelajar mengakibatkan mereka kurang yakin untuk menjalani Latihan Mengajar. Guru pelatih yang meletakkan jangkaan yang tinggi kepada pelajar akhirnya mendapati jangkaan tesebut tidak betul, seterusnya mengakibatkan tahap keyakinan mereka menurun. Walau bagaimanapun, setelah memahami sikap dan menyesuaikan diri dengan keadaan pelajar dan sekolah, akhirnya guru pelatih mampu menjalani Latihan Mengajar dengan jayanya. Sesungguhnya Latihan Mengajar merupakan medium yang amat penting untuk melatih bakal-bakal guru. Dengan menjalani latihan ini pelajar akan didedahkan kepada situasi sebenar suasana iklim sekolah dan juga profesyen perguruan.

Oleh itu, boleh disimpulkan di sini keyakinan adalah kepercayaan pada diri sendiri tanpa mengira jantina. Setiap manusia mempunyai kemahiran yang berbeza dan kecerdasan yang berbeza. Potensi diri mereka boleh diperkembangkan sekiranya ada usaha untuk memajukan diri mereka sendiri. Sebagai pelajar mereka perlu lebih bersikap terbuka dan mudah menerima nilai, konsep dan keyakinan baru. Setiap tindakan yang kita ambil memerlukan keyakinan terhadap diri yang tinggi supaya seseorang itu dapat segala masalah yang dihadapi. Ianya adalah perasaan dalaman yang boleh dipupuk dan disemai agar kita lebih percaya pada kemampuan diri sendiri. Justeru, yang membezakan antara seseorang yang berkeyakinan tinggi dengan seseorang yang kurang berkeyakinan adalah cara bagaimana seseorang itu mengatasi masalah takut mereka dan bagaimana dia menghadapinya. Keyakinan diri yang tinggi sangat penting bagi membantu membina kemahiran generik yang lain seperti kemahiran komunikasi, kemahiran kepimpinan dan sebagainya. Sebagai seorang guru pula, dengan adanya tahap keyakinan diri yang tinggi akan dapat membantu meningkatkan prestasi kerja guru sekaligus membantu menaikkan tahap prestasi akademik pelajar. Maklumat mengenai tahap keyakinan diri ini boleh dijadikan penanda aras untuk memastikan UUM mampu melahirkan graduan yang bersedia menghadapi cabaran globalisasi tanpa membelakangkan unsur pengukuhan spritual dan adat budaya.

\section{RUJUKAN}

Abdul Aziz, A., \& Abu, B. (2009). Tahap kesediaan guru pelatih UTM berkhidmat di Sabah dan Sarawak (Doctoral dissertation, Universiti Teknologi Malaysia).

Abdul, R., \& Sharifah. (2003). Penyemakan semula kurikulum untuk pendidikan alaf baru. International Conference on Teaching and Learning. (Doctoral dissertation, Fakulti Pendidikan, Universiti Kebangsaan Malaysia).

Ai, X. (2004). Creativity and academic achievement: An investigation of gender differences. Creativity Research Journal, 12(4), 329-337.

Arif, H., Khairriah, N., \& Abd Ghani, F. (2010). Profil personaliti guru cemerlang sekolah kebangsaan di daerah Kulaijaya. (Doctoral dissertation, Universiti Teknologi Malaysia).

Ayob, A. (2003). Kepentingan kemahiran generik di kalangan pekerja di industri elektrik/elektronik di Bayan Lepas, Pulau Pinang. (Doctoral dissertation, Universiti Teknologi Malaysia).

Barnett, J. J. (1994). Promotion management. Houghton Mifflin Company.

Donofrio, H. H., \& Davis, K. (2007). Oral communication across disciplines: adding value to academic pursuit and marketability.

Guay, F., Marsh, H. W., \& Boivin, M. (2003). Academic self-concept and academic achievement: developmental perspectives on their causal ordering. Journal of educational psychology, 95(1), 124.

Haruddin, H. (2004). Pengintegrasian aspek-aspek kemahiran generik dalam proses pengajaran dan pembelajaran bagi program kemahiran tinggi selaras dengan keperluan industri: satu kajian kes di Pusat Latihan Teknologi Tinggi (ADTEC) dari perspektif pengajar (Doctoral dissertation, Kolej Universiti Teknologi Tun Hussein Onn).

Harun, F. M. (2013). Keyakinan diri pelajar Diploma Pendidikan lepasan ijazah di Universiti Tun Hussein Onn Malaysia terhadap ICT (Doctoral dissertation, Universiti Tun Hussein Onn Malaysia).

Kamus Dewan. (4 ${ }^{\text {th }}$ ed.). (2005). Kuala Lumpur: Dewan Bahasa dan Pustaka.

Kartini, B. (2002). Sekolah Bestari: Pedagogi abad ke-21 dan profesionalisme guru. Jurnal Pendidikan Guru, Vol.15.

Krejcie, R. V., \& Morgan, D. W. (1970). Determining sample size for research activities. Educ Psychol Meas.

Naderi, H., Abdullah, R., Hamid, T. A., \& Aizan, T. (2008). Male and female intelligence among undergraduate students: does gender matter? Asian Journal of Scientific Research, 1(5), 539-543.

Robert, A. (2003). Rahsia membina keyakinan diri sendiri. Albaz Publishing \& Distribution Sdn. Bhd.

Yaakub, N. F., \& Elias, H. (2002). Job motivation and job performance: Case of recipients for excellent service in a higher education institution. Malaysian Management Review. Retrieved from http://mgv.mim.edu.my/mmrsearch/9906/990608.htm 
Yahaya, A., Karim, S. A., \& Yahaya, N. (2003). Hubungan gaya pembelajaran dengan pencapaian akademik pelajar di tingkatan empat Sekolah Menengah Teknik Negeri Sembilan.

Yusoff, M. (2007). Tahap keyakinan kemahiran generik di kalangan pelajar: kajian kes di salah sebuah kolej kediaman kediaman di UTM, kampus Skudai, Johor Bahru, Malaysia. (Doctoral dissertation, Fakulti Pendidikan. Universiti Teknologi Malaysia).

Zalinda, I., Zaini, A., \& Abdul Kadir, A. (2011). Ciri-ciri guru berkualiti: satu tinjauan di beberapa buah sekolah di daerah Manjung, Perak. (Doctoral dissertation. Universiti Pendidikan Sultan Idris).

Zanzali, A., Azlan, N., \& Asri Atjeng, H. (2010). Faktor-faktor yang mempengaruhi keyakinan guru pelatih semasa menjalani latihan mengajar, 1-13.

Zareh, H. (1994). The relationships between achievement of motivation, self-esteem and gender among high school of students. University of Tarbiyat Moalem, Tehran, Iran. 